\title{
TRANSLATING RISK TO PREVENTABLE BURDEN BY ESTIMATING NUMBERS OF BICYCLING INJURIES PREVENTABLE BY SEPARATED INFRASTRUCTURE ON A TORONTO, ONTARIO CORRIDOR
}

\author{
Calum Thompson $^{1}$, Michael Branion-Calles ${ }^{2}$, M. Anne Harris ${ }^{1,2 *}$ \\ ${ }^{1}$ Dalla Lana School of Public Health, University of Toronto, Toronto, Canada \\ ${ }^{2}$ School of Occupational and Public Health, Ryerson University, Toronto, Canada \\ Corresponding author: M. Anne Harris, anne.harris@ryerson.ca
}

\begin{abstract}
Objectives: Bicycling is a form of active transportation with several health benefits but carries a high risk of injury compared to other transportation modes. Safety intervention evaluations often produce results in the form of ratios, which can be difficult to communicate to policy-makers. The primary objective of this study was to estimate the number of preventable bicycling injuries on an urban corridor by separating bicycling infrastructure.
\end{abstract}

Methods: Stakeholders identified a key corridor with multiple segments having bicycling infrastructure but most of the corridor lacking similar infrastructure. We counted bicyclist volume along this route and used secondary data to supplement counts missing due to COVID-19. We used two reference studies conducted in Toronto, Ontario to estimate benefit of separated bicycling infrastructure and applied this to a city-wide estimate of baseline risk of injury per kilometre bicycled, which used a combination of secondary data sources including police, health care, and health and travel survey data. We adjusted estimates to account for increased bicyclist volume during and following the COVID-19 pandemic. We constructed "plausible intervals" (PI) to express uncertainty in estimates, calculated from upper and lower bounds estimated from the secondary data inputs.

Results: We estimated installation of fully separated cycle tracks along one Toronto corridor would prevent approximately 152.9 [PI: 61.2-212.7] injuries and 0.9 fatalities over a 10-year period for current ridership. As ridership increases, fully separated cycle tracks would prevent between approximately 159.3 [PI: 63.8-221.6] to 411.5 [PI: 253.3-572.6] injuries, and 1.0 [PI: 0.2-2.2] to 2.4 [PI: 0.5-5.7] fatalities over a 10-year period.

Discussion: Our results underscore the benefits of separated bicycling infrastructure. We identify several caveats for our results, including the limitations of studies used to estimate relative risk of infrastructure. Our method could be adapted for use in other cities or along other corridors. Finally, we discuss the role of preventable burden estimates as a knowledge translation tool.

Keywords: Bicycling; Injuries; Risk, Prevention; Transportation; COVID-19

\section{Introduction}

The COVID-19 pandemic has placed new focus on bicycling as a physically distanced, active form of travel. ${ }^{1}$ Safety concerns can deter bicycling, ${ }^{2}$ as injuries per kilometre are higher than other modes. ${ }^{3-5}$ Prior reviews evaluated the benefits of physically separated infrastructure in reducing injury or collision risk for bicyclists. $^{6-8}$ Inconsistencies in methodology can make interpretation and comparison of different infrastructure types challenging. Overall, literature reviews have concluded that physically separated cycle tracks reduce injury and collision risk for bicyclists. ${ }^{9}$ Reviews have also reported protective effects of painted cycle lanes (i.e., a painted lane along a roadway designated exclusively for bicyclists) ${ }^{9}$ in reducing injury and collision risk compared to streets without bicycling infrastructure. ${ }^{8}$ From a 
public health perspective, physically separated bicycling infrastructure has numerous advantages because it is populationbased, can be passively engaged by users, and can accrue benefits over time following implementation..$^{10,11}$

Prior reviews have recommended the adoption of consistent terminology for bicycling infrastructure (e.g., $\left.{ }^{9}, 10\right)$. In 2020, Winters et al. ${ }^{12}$ introduced the Canadian Bikeway Comfort and Safety (Can-BICS) classification system to ensure consistent nomenclature. In this analysis, we use terminology consistent with Can-BICS, with cycle tracks used to denote physical separation and bicycle lanes or cycle lanes to indicate permeable infrastructure (e.g., painted lines). ${ }^{12}$ Where local convention uses terminology not fully consistent with this nomenclature, we indicate local usage in quotes (e.g., "cycle tracks" that are not physically separated).

Few peer-reviewed studies have analyzed the burden of bicycling injury in Toronto, Ontario. More than two decades ago, Aultman-Hall et al. conducted a survey of 1360 Toronto bicyclists, who reported 666 collisions in the preceding 3 years and 482 falls in the preceding twelve months. ${ }^{3}$ This study concluded that Toronto bicyclists had rates of collision 26-68 times higher than motor vehicles, ${ }^{3}$ and indicated that the built environment contributed to this increased risk. In the intervening years, the built environment and the bicycling population of Toronto continue to evolve.

Communicating findings is a challenge for public health intervention research. Studies evaluating the effectiveness of interventions often report ratios, including odds ratios (e.g., ${ }^{6,7,13,14}[\mathrm{OR}]$ ) and others (e.g., rates $^{15}$ or risk ratios $\left.{ }^{16,17}\right)$. These can be difficult to interpret for potential policy- and decision-makers. Expressing ratio findings in different ways may improve understanding. Raw count estimates and percentages, including analyses of burden, can illustrate the magnitude of risk effects and communicate these in a way that may be more vivid than ratios. ${ }^{18-20}$ However, these estimates are often constructed at the national and international scale and there are few examples of simplified burden calculations employed at the local (e.g., individual city) level.

The current study responded to stakeholder need (City Building Ryerson and Metcalf Foundation) for data on numbers of preventable injuries by separating bicycling infrastructure in Toronto. The primary objective was to estimate absolute numbers of bicycling injuries on an urban corridor preventable by bicycling infrastructure over ten years following a complete implementation, using previously published intervention evaluations and a combination of primary and secondary data. ${ }^{21}$

\section{Methods}

To select a Toronto corridor for evaluation, we consulted with local advocacy and municipal government stakeholders in mid2019. ${ }^{21}$ The process identified Bloor St. to Danforth Ave. from Parkside Dr. in the West to Dawes Ave. in the East (Figure 1) as a high priority for intervention. At the time, bicycling infrastructure was limited 
and intermittent on this corridor, and our analyses included only those segments without infrastructure. To estimate the expected burden of injury on target segments, and the alleviated burden preventable with infrastructure intervention, we collected primary data on bicycle volumes and compiled data from eight distinct secondary and literature sources. Table 1 summarizes the calculations and data sources used. Below, we detail special methodological considerations and details of calculations.

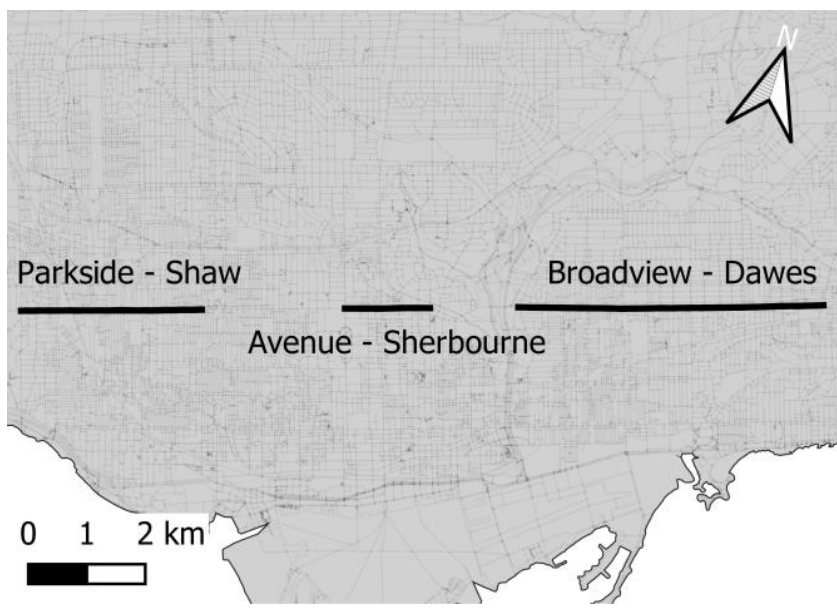

Figure 1. Study area (Bloor Street to Danforth Avenue) with included street segments (Parkside Drive to Shaw Street, Avenue Road to Sherbourne Street, Broadview Avenue to Dawes Road) highlighted. Manual counts were conducted at the endpoints of each segment from September 2019 to March 2020

\section{Bicycle volumes: modelling automated count data to supplement primary collection}

Our research assistant conducted 20-minute counts at segment endpoints along the corridor between September 11, 2019 and March 13, 2020, at which point COVID-19 interrupted data collection. To impute ridership for seasons and times of day without manual data collection, we used the City of
Toronto's Open Data Bicycling Volume dataset containing automatic counts at three locations. ${ }^{22}$ We modeled daily count data based on hour of the day, season, and day of the week, and modeled annual volumes from average daily volumes. Because the count stations are adjacent to those we modeled, we used a LOESS smoother ${ }^{23}$ as it can capture the complex, nonlinear patterns present in the automatic counter data when aggregated and stratified by different time periods and temporal conditions. ${ }^{23}$ The technical component of our public report provides additional details about modeled volumes. ${ }^{21}$ Total segment bicycle rider counts were derived from the extrapolated count model for each respective segment, by calculating the mean of segment endpoints. Bicycle rider counts from our model indicated Bloor-Danforth supports $1,463,626$ bicyclists annually. ${ }^{21}$

We considered bicycle volume increases resulting from the COVID-19 pandemic. Early survey reports indicated substantial public transit hesitancy in response to the COVID-19 pandemic, with $23 \%$ of public transit users indicating they would avoid Toronto transit until a vaccine is available. ${ }^{24}$ Some of these users may divert to other modes, including bicycling. We also anticipated that new bicycling infrastructure along Bloor-Danforth installed in summer of $2020^{21}$ would attract additional riders. To account for this expected increase, we applied four increased bicycle ridership scenarios to our estimates: volume increases of $10 \%, 20 \%, 33 \%$, and $50 \%$ of current ridership. As an outer threshold, a ridership increase of $1000 \%$ was considered given past reported volume increases 
Table 1. Summary of calculations and data sources used to estimate bicycling injuries preventable by bicycling infrastructure on a target corridor in Toronto, Canada.

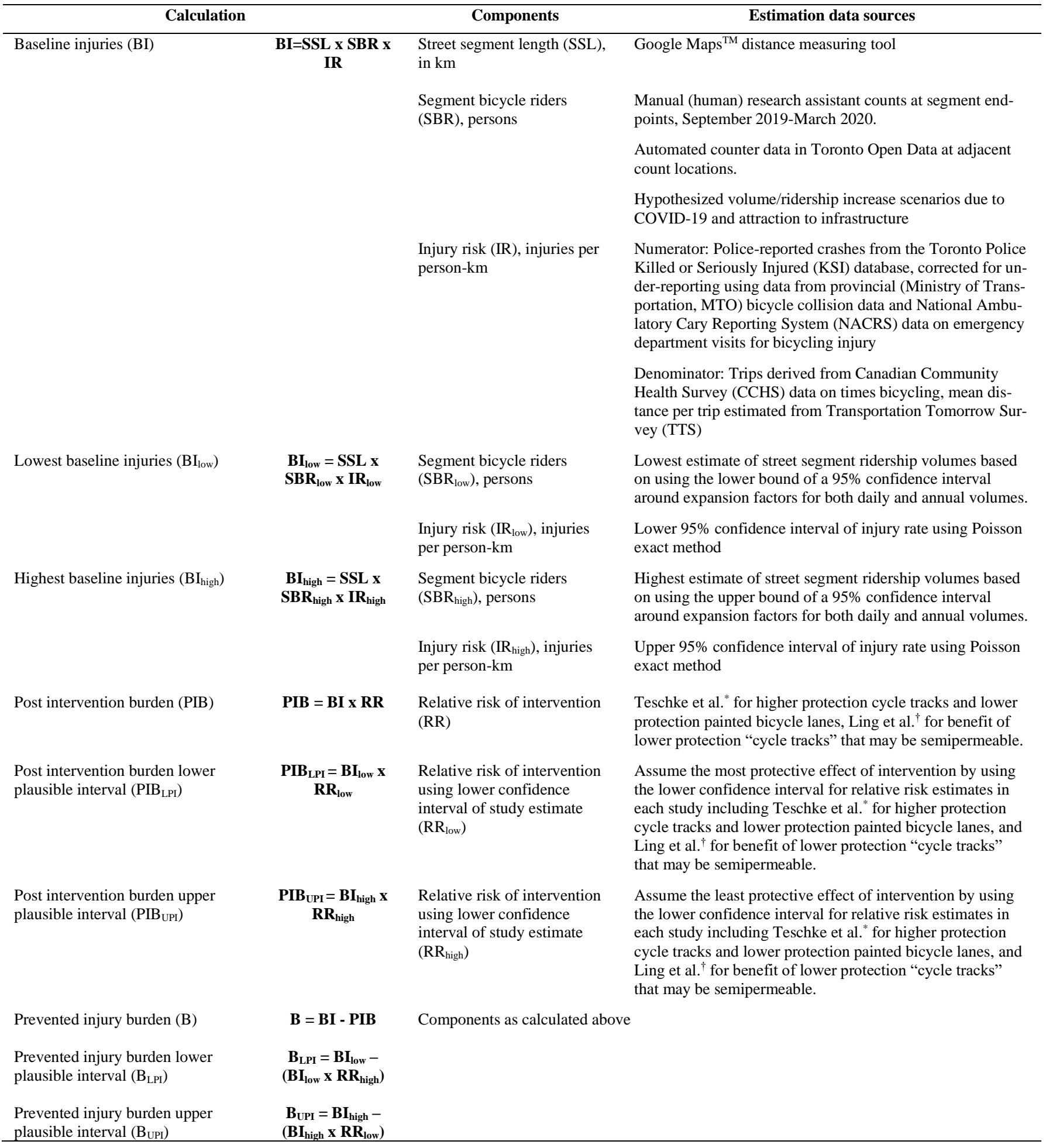

*Teschke et al. 2012. American Journal of Public Health. Vol 102 (12), pp 2336-2343.

${ }^{\dagger}$ Ling et al. 2020. Accident Analysis \& Prevention. Vol 135 (2020) 
following implementation of cycle tracks on Richmond and Adelaide streets (which may have particularly represented bicycle traffic diversion in addition to new riders). ${ }^{25}$

\section{Estimating baseline bicycling injury risk with numerators and denominators}

We calculated a city-wide estimate of baseline injury risk (Table 1) by compiling data on the number of bicyclist injuries or fatalities across Toronto (numerator) and the total number of kilometers travelled by bicyclists in Toronto during the same period (denominator). While there could be many ways to define injury severity sufficient to warrant public health concern, we targeted injuries that would require a visit to emergency departments.

\section{Injuries to cyclists: correcting for underreporting in police data}

Toronto Police Services (TPS) records summarize bicyclist collisions in their "Killed or Seriously Injured" (KSI) dataset. ${ }^{26}$ This dataset is a subset of policereported injuries where a major or fatal injury has occurred. ${ }^{26}$ Even when they include broader range of injury severity, police-reported crashes systematically miss bicycling injuries, particularly when they are non-fatal and do not involve motor-vehicles. ${ }^{27}$ To address the problem of unreported injuries requiring emergency department (ED) visits in the absence of Toronto-specific hospital data, we estimated a correction factor using provincial data. We examined the ratio between Ontario policereported bicycle crashes from the Ontario
Ministry of Transportation (MTO) annual collision statistics (2014-2017) ${ }^{28}$ and bicycle injuries treated in Ontario EDs during the same period, compiled by the Canadian Institute for Health Information. ${ }^{29}$ The observed ratio between ED injuries and MTO summarized police-reported collisions was 11.2. We then assumed this Ontario-wide ratio would apply to Toronto. We multiplied the 2014-2017 total non-fatal TPS KSI bicycling crashes by the correction factor. Between 2014 and 2017 TPS recorded 181 injuries and 12 fatalities. After applying the correction factor, we estimated 2,019 bicyclist injuries in Toronto between 2014-2017, or 504 injuries each year.

\section{Risk denominators: trips and kilometres}

Denominator calculations were performed in $\mathrm{R}$ version 4.0.2, ${ }^{30} \mathrm{using}$ two data sources to estimate total kilometres bicycled annually in Toronto. We analyzed the Canadian Community Health Survey (CCHS) 2014 cycle $^{31}$ public use microdata file (PUMF), subset to respondents within the Toronto Public Health Unit, and tallied the number of bicycling trips to work/school and for leisure (defined as times bicycling "not for work). We used CCHS survey weights to calculate a weighted sum, tallying 47,039,804 annual Toronto bicycle trips.

We used the Transportation Tomorrow Survey (TTS) to estimate average trip length for Toronto bicyclists. ${ }^{32}$ TTS aggregates data for several Ontario municipalities, ${ }^{32}$ but we assumed that mean bicycling trip length would be comparable in Toronto. Trip length was calculated using a 
weighted mean for Manhattan lengths to simulate city blocks. ${ }^{33}$ Average bicycle trip length was $4.3 \mathrm{~km}$. Number of trips were multiplied by average trip length to yield an estimate of annual kilometres travelled by bicycle in Toronto: 202,318,197 km.

\section{Baseline injury risk per person-km}

Dividing 504 injuries by 202,318,197 km, we obtained a Toronto baseline injury risk estimate of 0.25 per 100,000 person-km. We applied a safety-in-numbers ${ }^{34,35}$ effect to injury risk. The safety-in-numbers effect postulates that risk of injury declines with increasing volumes. ${ }^{34,35}$

\section{Relative risk of intervention}

We drew our ratio estimates from two prior studies ${ }^{13,16}$ that collected data in Toronto. Teschke et al. ${ }^{13}$ found cycle tracks (defined as physically separated cycle lanes) offered significant protection $(\mathrm{OR}=0.11,95 \% \mathrm{CI}$ : $0.02,0.54)$. They found painted cycle lanes, when implemented without parked cars, offered less protection $(\mathrm{OR}=0.54$, 95\% CI: $0.29,1.01) .{ }^{13}$ Ling et al. ${ }^{16}$ focused on local infrastructure labeled as "cycle tracks" (not consistently physically separated, compared to other jurisdictions) $)^{9,12}$ recording a protective association $(\mathrm{OR}=$ $0.62,95 \%$ CI: $0.44,0.89$ ).

We used the OR estimate for fully physically separated cycle tracks from Teschke et al. ${ }^{13}(0.11)$ to approximate relative risk (or relative rate) for a "high protection scenario". ORs are often used to approximate relative risk when the outcome is rare. ${ }^{36} \mathrm{Bi}$ cycle collisions are very rare in Toronto given the high bicycling volume. The OR (0.62) from Ling et al.'s ${ }^{16}$ evaluation of Toronto-implemented "cycle tracks"13 was used to approximate a "lower protection" scenario. Finally, painted cycle lanes with no parked cars were termed "lower protection 2" using the OR observed by Teschke et al. (0.54). ${ }^{13}$ These interventions would result in an estimated $89 \%, 38 \%$, or $46 \%$ reduction in risk of crash, respectively.

\section{Conveying uncertainty: plausible intervals}

In compiling a wide range of secondary data with a multipart calculation (Table 1), there is no standard methodology available to apply a measure of sampling error to our overall burden calculation. We thus presented only point estimates to stakeholders in our public report. ${ }^{21}$ However, given the value of demonstrating the uncertainty inherent in estimation, we developed a "plausible interval" (PI) measure, detailed in Table 1, to summarize upper and lower bounds on estimates from the component data sources.

\section{Results}

Table 2 summarizes ten-year projections of injury burden along previously unprotected segments of the target corridor. Without intervention, hundreds of injuries requiring emergency department visits can be expected (Table 2). The burden of injuries and fatalities prevented by infrastructure interventions is shown in Figures 2 and 3, respectively. Overall, largest reduction in injury burden would occur by implementing high protection, fully separated 
bicycling infrastructure, ${ }^{13}$ preventing an estimated 152.9 [PI: 99.9-167.4] injuries at current ridership and as many as 411.5 [PI: 268.9-450.7] injuries with extremely increased ridership of $1000 \%$. Similarly, high protection infrastructure could prevent 0.9 [PI: 0.8-0.9] fatalities over 10 years, and as many as 2.4 [PI: 2.1-2.5] with increased ridership of $1000 \%$. Lower protection cycle tracks ${ }^{16}$ could prevent as many as 175.7 [PI: 143.5-205.3] injuries
(Figure 2) and 1.0 [PI: 0.1-1.0] fatalities (Figure 3) over 10 years with this extremely high ridership increase, while lower protection painted lanes ${ }^{13}$ could prevent 212.7 [PI: 100.5-293.0] injuries (Figure 2) and 1.2 [PI: 1.0-1.5] fatalities over 10 years (Figure 3 ).

Table 2: Ten-year estimated numbers of injuries and fatalities along Bloor Street to Danforth Avenue, with and without (baseline) installation of safer bicycling infrastructure over 10 years, with estimates of relative risk (RR) provided by interventions derived from literature sources.

\begin{tabular}{|c|c|c|c|c|}
\hline \multicolumn{5}{|c|}{10 Year Injury Burden [plausible interval] } \\
\hline $\begin{array}{l}\text { Ridership } \\
\text { Projection }\end{array}$ & Baseline & $\begin{array}{l}\text { High Protection } \\
\quad(\mathbf{R R}=\mathbf{0 . 1 1})^{*} \\
\text { Fully Separated }\end{array}$ & $\begin{array}{c}\text { Lower protection } 1 \\
(\mathbf{R R}=\mathbf{0 . 6 2})^{\dagger} \\
\text { Intermittently Separated }\end{array}$ & $\begin{array}{c}\text { Lower protection } 2 \\
(\mathbf{R R}=\mathbf{0 . 5 4})^{* *} \\
\text { Painted lanes }\end{array}$ \\
\hline Current & $171.8[133.1-217.1]$ & $18.9[2.7-117.2]$ & $106.5[58.6-193.2]$ & $92.8[38.6-219.2]$ \\
\hline $10 \%$ increase & $179.0[138.7-226.2]$ & $19.7[2.8-122.1]$ & $111.0[61.0-201.3]$ & $96.7[40.2-228.4]$ \\
\hline $25 \%$ increase & 189.1 [146.5 - 238.9] & $20.8[2.9-129.0]$ & $117.264 .5-212.7]$ & $102.1[42.5-241.3]$ \\
\hline $33 \%$ increase & $194.2[150.5-245.4]$ & $21.4[3.0-132.5]$ & $120.466 .2-218.4]$ & $104.9[43.6-247.9]$ \\
\hline $50 \%$ increase & $204.5[158.5-258.4]$ & $22.5[3.2-139.6]$ & $126.8[69.7-230.0]$ & $110.4[46.0-261.0]$ \\
\hline $1000 \%$ increase & $462.4[358.3-584.3]$ & $50.9[7.2-315.5]$ & $286.7[157.7-520.0]$ & $249.7[103.9-590.1]$ \\
\hline \multicolumn{5}{|c|}{10 Year Fatality Burden [plausible interval] } \\
\hline $\begin{array}{l}\text { Ridership } \\
\text { Projection }\end{array}$ & Baseline & $\begin{array}{l}\text { High Protection } \\
\quad(\mathbf{R R}=\mathbf{0 . 1 1})^{*} \\
\text { Fully Separated }\end{array}$ & $\begin{array}{c}\text { Lower protection } 1 \\
(\mathbf{R R}=\mathbf{0 . 6 2})^{\dagger} \\
\text { Intermittently Separated }\end{array}$ & $\begin{array}{c}\text { Lower protection } 2 \\
(\mathbf{R R}=\mathbf{0 . 5 4})^{* *} \\
\text { Painted lanes }\end{array}$ \\
\hline Current & $1.0[0.4-2.2]$ & $0.1[0.0-1.2]$ & $0.6[0.2-1.9]$ & $0.6[0.1-2.2]$ \\
\hline $10 \%$ increase & $1.1[0.4-2.2]$ & $0.1[0.0-1.2]$ & $0.7[0.2-2.0]$ & $0.6[0.1-2.3]$ \\
\hline $25 \%$ increase & $1.1[0.5-2.4]$ & $0.1[0.0-1.3]$ & $0.7[0.2-2.1]$ & $0.6[0.1-2.4]$ \\
\hline $33 \%$ increase & $1.2[0.5-2.4]$ & $0.1[0.0-1.3]$ & $0.7[0.2-2.2]$ & $0.6[0.1-2.5]$ \\
\hline $50 \%$ increase & $1.2[0.5-2.6]$ & $0.1[0.0-1.4]$ & $0.8[0.2-2.3]$ & $0.7[0.1-2.6]$ \\
\hline $1000 \%$ increase & $2.7[1.1-5.8]$ & $0.3[0.0-3.1]$ & $1.7[0.5-5.2]$ & $1.5[0.3-5.9]$ \\
\hline
\end{tabular}

\section{Discussion}

This analysis showed that a substantial number of injuries can be prevented by implementation of physically separated bicycling infrastructure. During our analyses, the City of Toronto rapidly implemented both separated and semi-permeable bicycle infrastructure along the Bloor-Danforth study route, in response to COVID-19..$^{21,37}$ As such, our calculated estimates may form a preliminary projection of the benefits of 
this newly installed (and designated as "temporary") ${ }^{37}$ infrastructure, if it is made permanent. Ongoing data collection along the route will test the accuracy of projections. This project is unique in its attempt to quantify hypothetical benefits of preventive bicycling infrastructure intervention prior to implementation. Other studies have attempted to quantify benefits after implementation, including improved physical activity ${ }^{38}$ and injuries prevented. ${ }^{8}$ In studies projecting benefits of infrastructure, the focus has been on presenting an economic case for infrastructure interventions. ${ }^{39}$ However, it may also support communication to incorporate injury and fatality burden impacts.

The methods outlined in this study could be adapted to other city corridors and geographic regions as our public report included a downloadable, modifiable spreadsheet. $^{21}$ Our risk calculations estimated baseline risk for Toronto as whole. While this will allow estimated risk per kilometre travelled to apply to other locations in the same city, it assumes risk is homogeneous throughout the municipality. In reality, crash and injury risk are heterogenous over both space and time, but this variability is not discernible from the secondary data sources we relied on. Spatial analyses of Toronto bicycling crashes rely on police reported crashes. ${ }^{16} \mathrm{We}$ used secondary data to correct for the crucial problem of underreporting of bicycling injuries in police data. ${ }^{40}$ This secondary data correction relied on provincial rather than municipal data because health care system data are summarized at the provincial rather than municipal level. Incorporation of health care system utilization data to capture traffic injury, particularly of active transportation users, would strongly improve municipal road safety surveillance programs. ${ }^{41}$ However, we note that there can be impacts of injury that do not require interaction with the health care system, and these injuries could be assessed by primary data collection and surveillance approaches.

Our report presents decision-makers with absolute estimates of the number of injuries preventable with design intervention. There exists no standard method to evaluate knowledge translation interventions and it is difficult to assess their success. ${ }^{42}$ One metric could be uptake of public-facing materials. We produced a webinar and a report, with 75 people attending the webinar and 72 downloads of the report between September 29 and November 18, 2020. Considering substantial portions of the newly implemented bicycle infrastructure on this corridor were designated as "temporary", ${ }^{37}$ an opportunity to evaluate this project as a knowledge translation product will arise when the permanency of the implemented infrastructure is debated by municipal government (anticipated for 2021). Testing reactions before and after reading the technical report could be a potential way to evaluate its impact. ${ }^{43} \mathrm{We}$ must acknowledge, however, that there may be an element of "study fatigue" on the part of community stakeholders when new studies are required each time safe infrastructure projects are considered.

Our analysis compiles multiple data sources collected across different years to derive high-level estimates. As such, there 
are several limitations that must be acknowledged when interpreting our rebe used to approximate relative rates or risk sults. Our calculations assume that odds ratios (ORs) from reference studies ${ }^{13,16}$ can ratios (RRs).
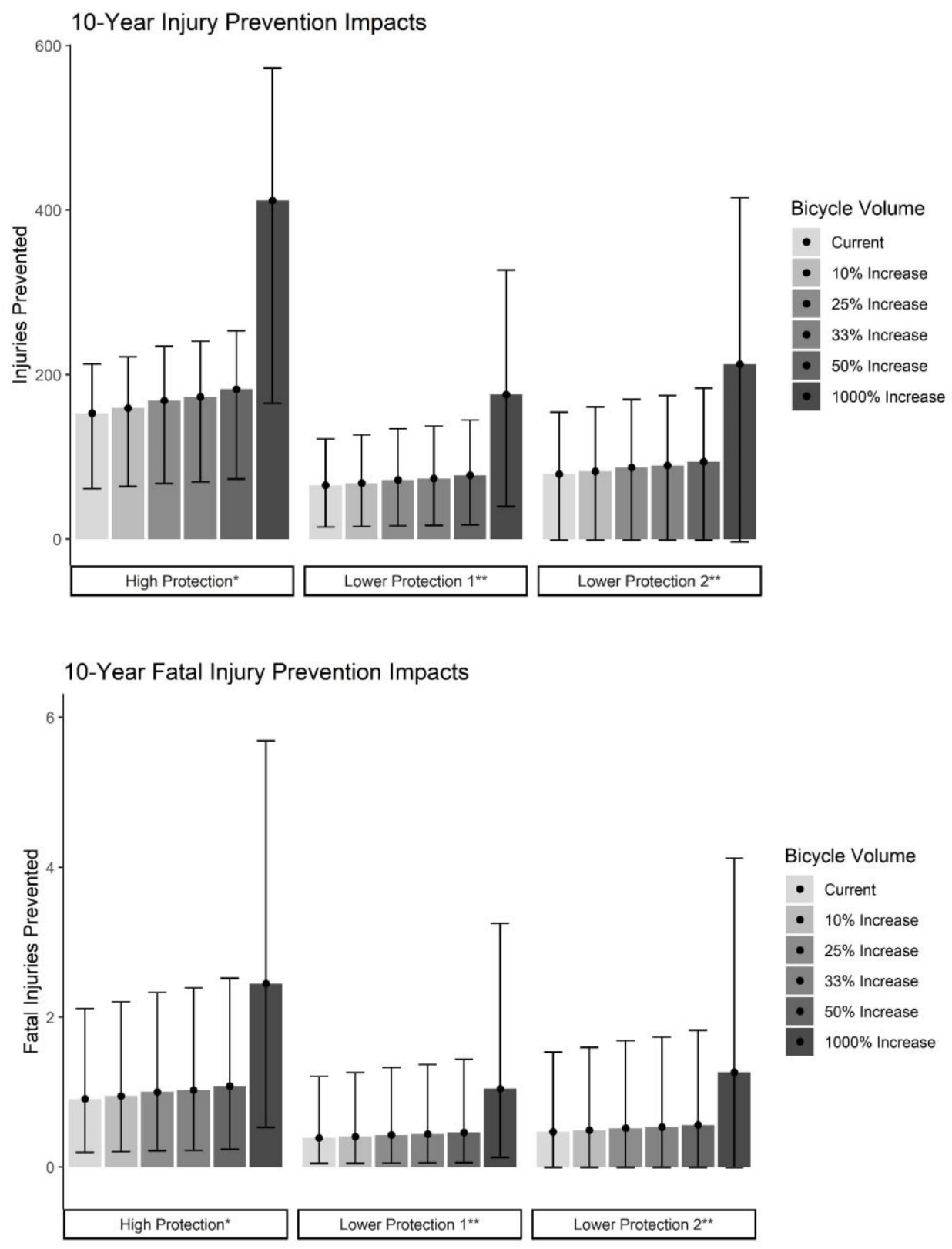

\footnotetext{
* Cycle tracks, per Teschke et al. 2012. American Journal of Public Health. Vol 102 (12), pp 2336-2343.

** Cycle tracks, per Ling et al. 2020. Accident Analysis \& Prevention. Vol 135 (2020).

*** Painted cycle lanes, per Teschke et al. 2012. American Journal of Public Health. Vol 102 (12), pp 2336-2343
}

Figure 2 (Top) and Figure 3 (Bottom). Top: Ten-year estimates of injuries preventable by installing bicycling infrastructure along Bloor Street and Danforth Ave in Toronto, Canada. Whiskers represent "plausible intervals" estimated from upper and lower bounds of calculation inputs. Bottom: Ten-year estimates of fatalities preventable by installing bicycling infrastructure along Bloor Street and Danforth Ave in Toronto, Canada. Whiskers represent "plausible intervals" estimated from upper and lower bounds of calculation inputs. 
This assumption depends on the generalizability of the original study population and the low incidence of the outcome. ${ }^{44}$ Our use of studies collecting Toronto data and the overall low incidence of bicycling injury can address these assumptions.

The two reference studies ${ }^{13,16}$ we relied on were designed differently, complicating comparison of resulting ORs. At the time of the Teschke et al (2012) ${ }^{13}$ study, much of the current bicycling infrastructure found in Toronto had not been implemented. While guidance on "cycle track" nomenclature entails physical separation, ${ }^{12}$ Toronto has a range of "cycle tracks" which are permeable or semipermeable. It was this variety of styles implemented in 2013 and 2014 that were assessed directly by Ling et al. ${ }^{16}$ Given that effects of infrastructure can vary strongly by implementation and design, ${ }^{7,9,10}$ it will be crucial to monitor impacts and problems with any implemented protected designs.

This project entailed consultation with local stakeholders to identify the target corridor. The corridor was considered a primary target for intervention, supported by the later street reallocation efforts during COVID-19 response. However, this process may not give sufficient attention to equity considerations ${ }^{45,46}$ which must be considered along with existing ridership, safety, connectedness, and accessibility. Separated bicycling infrastructure may also confer injury protection benefits to other road users including motor vehicle occupants (e.g., reduced speed) and pedestrians through additional separation ${ }^{47}$ not captured in this analysis. We were limited in measuring safety effects in terms of injuries prevented and did not assess other aspects of safety including harassment, particularly as experienced by marginalized and racialized people. ${ }^{48}$

We used our city-wide estimates of injury risk as a baseline before applying relative risk of intervention at locations with no bicycling infrastructure. This does not factor in spatial variation in risk, and because some Toronto streets already have cycling infrastructure, a city-wide estimate may be an underestimate of local rates, if locations without infrastructure have higher injury risk. This limitation would tend to underestimate benefits of intervention. In contrast, our estimates of bicycling trip denominators may be an undercount because of incomplete data on bicycling for utilitarian purposes other than work or school (i.e., CCHS does not have a full accounting of all bicycling trips), which could tend to overestimate baseline risk and benefits of intervention.

Our approach to recognizing the impact of COVID-19 was to include projections of possible increases in bicycling volumes in response to the pandemic, in addition to overall attraction to improved infrastructure. ${ }^{25}$ Ongoing volume counts will help assess whether these projections were reasonable. Our analysis only considered bicycle volume and does not incorporate possible changes in volume of other modes. It is not yet known if deterrence from public transit to personal motor vehicles ${ }^{49}$ will persist into pandemic recovery, or whether this may lead to locally increased motor vehicle volumes on this target corridor. While 
motor vehicle volumes declined during early COVID-19 interventions, possible increased speeds of motor vehicle traffic, resulting from decreased volumes might paradoxically have increased risk to vulnerable road users. ${ }^{50}$

Consideration of statistical error is challenging with this approach, and our method of constructing a plausible interval has limitations. The bounds we calculated represent scenarios which, based on our methodology, are the upper and lower bounds of estimated injuries prevented and should not be interpreted as a confidence interval around a statistical parameter in a frequentist framework. ${ }^{51}$ The bounds may over- or underestimate true error depending on underlying distributions and variability. There may be other ways to impress upon knowledge users the uncertainty around estimates or what can be expected as a reasonable, plausible range. Future studies could attempt simulation (e.g., ${ }^{52,53}$ ) to model error, but improving primary collection of data used for calculation inputs could be a better use of resources.

This analysis helps to identify data sources needed for ongoing assessment and surveillance of bicycling injury. We relied on a variety of data sources to approximate numerators and denominators of risk. For numerator data, inclusion of injuries requiring ED and hospital visits may enable a more complete assessment of injury impacts of interventions. ${ }^{54}$ For denominator data, expanded locations of volume count data collection with more detailed demographic data for all modes of transportation will provide more accurate denominators for risk estimates and enable more nuanced analyses of populations affected. Because automated counts do not entail demographic detail, these could be supplemented with manual counts, including those made with video footage. ${ }^{55} \mathrm{We}$ also advocate for the adoption of a national travel survey to improve overall estimates of injury risk and rates at the population level. $^{56}$

\section{Acknowledgements}

This project was funded by the Metcalf Foundation in a grant to Ryerson City Building Institute (now City Building Ryerson), which sub-granted this project to $\mathrm{MAH}$ as PI. Funding also came from Ryerson University's Work-Study Research Assistant program, and we thank Naing Myint for her contributions collecting data through field counting, and Meghan Winters and Linda Rothman for advice on primary data collection.

Communication of the scientific findings was led by City Building Ryerson, we acknowledge our team members Claire Nelischer, Claire Pfieffer, and Cherise Burda for creating and communicating public-facing lay-oriented materials. We are grateful to Meghan Winters for providing a scientific review of the technical report and to two anonymous reviewers for their detailed comments on earlier drafts of this manuscript.

\section{References}

1. Sui W, Prapavessis H. COVID-19 has created more cyclists: How cities can keep them on their bikes. The Conversation 2020 [Date accessed 2021 May 12]. Available from: https://theconversation.com/covid-19-has-created-more-cyclists-how-cities-can-keep-them-on-their-bikes-137545 
2. Winters M, Babul S, Becker HJEH, et al. Safe Cycling: How Do Risk Perceptions Compare With Observed Risk? Canadian Journal of Public Health 2012;103:S42-S7. Available from:

https://doi.org/10.1007/BF03403834

3. Aultman-Hall L, Kaltenecker MG. Toronto bicycle commuter safety rates. Accident Analysis \& Prevention 1999;31:675-86. Available from: https://doi.org/10.1016/S0001-4575(99)00028-7

4. Beck LF, Dellinger AM, O'Neil ME. Motor Vehicle Crash Injury Rates by Mode of Travel, United States: Using Exposure-Based Methods to Quantify Differences. American Journal of Epidemiology 2007;166:2128. Available from: https://doi.org/10.1093/aje/kwm064

5. Toronto Public Health. Pedestrian and Cyclist Safety in Toronto 2015 Available from: https://www.toronto.ca/legdocs/mmis/2015/hl/bgrd/backgroundfile-81601.pdf

6. Wall SP, Lee DC, Frangos SG, et al. The effect of sharrows, painted bicycle lanes and physically protected paths on the severity of bicycle injuries caused by motor vehicles. Safety 2016;2:26. Available from: https://www.ncbi.nlm.nih.gov/pmc/articles/PMC5858726/

7. Cicchino JB, McCarthy ML, Newgard CD, et al. Not all protected bike lanes are the same: Infrastructure and risk of cyclist collisions and falls leading to emergency department visits in three US cities. Accident Analysis \& Prevention 2020;141:105490. Available from: https://doi.org/10.1016/j.aap.2020.105490

8. Bhatia D, Richmond SA, Loo CJ, Rothman L, Macarthur C, Howard A Examining the impact of cycle lanes on cyclist-motor vehicle collisions in the city of Toronto. Journal of Transport \& Health 2016;3:523-8. Available from: https://doi.org/10.1016/i.jth.2016.04.002

9. DiGioia J, Watkins KE, Xu Y, Rodgers M, Guensler R. Safety impacts of bicycle infrastructure: A critical review. Journal of Safety Research 2017;61:105-19. Available from: https://doi.org/10.1016/j.jsr.2017.02.015

10. Reynolds CC, Harris MA, Teschke K, Cripton PA, Winters M. The impact of transportation infrastructure on bicycling injuries and crashes: a review of the literature. Environmental Health 2009;8:47. Available from: https://doi.org/10.1186/1476-069X-8-47

11. Chipman ML. Hats off (or not?) to helmet legislation. Canadian Medical Association Journal 2002;166:602-602. Available from: https://pubmed.ncbi.nlm.nih.gov/11898940

12. Winters M, Zanotto M, Butler G. The Canadian Bikeway Comfort and Safety (Can-BICS) Classification System: A common naming convention for cycling infrastructure. Health Promotion and Chronic Disease Prevention in Canada 2020;40:288-93. Available from: https://pubmed.ncbi.nlm.nih.gov/32909939

13. Teschke K, Harris MA, Reynolds CC, et al. Route infrastructure and the risk of injuries to bicyclists: a case-crossover study. American journal of Public Health 2012;102:2336-43. Available from:

https://doi.org/10.2105/AJPH.2012.300762

14. Romanow NT, Couperthwaite AB, McCormack GR, Nettel-Aguirre A, Rowe BH, Hagel BE. Environmental determinants of bicycling injuries in Alberta, Canada. Journal of Environmental and Public Health 2012;2012. Available from: https://doi.org/10.1155/2012/487681

15. Bhatia R, Wier M. "Safety in Numbers" re-examined: Can we make valid or practical inferences from available evidence? Accident Analysis \& Prevention 2011;43:235-40. Available from: https://doi.org/10.1016/j.aap.2010.08.015

16. Ling R, Rothman L, Cloutier M-S, Macarthur C, Howard A. Cyclistmotor vehicle collisions before and after implementation of cycle tracks in Toronto, Canada. Accident Analysis \& Prevention 2020;135:105360. Available from: https://www.sciencedirect.com/science/article/abs/pii/S000145751930658X
17. Lusk AC, Furth PG, Morency P, Miranda-Moreno LF, Willett WC, Dennerlein JT. Risk of injury for bicycling on cycle tracks versus in the street. Injury Prevention 2011;17:131-5. Available from: http://dx.doi.org/10.1136/ip.2010.028696

18. Grant RL. Converting an odds ratio to a range of plausible relative risks for better communication of research findings. British Medical Journal 2014;348:f7450. Available from: https://www.bmj.com/content/bmj/348/bmj.f7450.full.pdf

19. Tenny S, Hoffman MR. Relative Risk. StatPearls Internet: StatPearls Publishing; 2020. Available from: https://www.ncbi.nlm.nih.gov/books/NBK430824/

20. Lim SS, Vos T, Flaxman AD, et al. A comparative risk assessment of burden of disease and injury attributable to 67 risk factors and risk factor clusters in 21 regions, 1990-2010: a systematic analysis for the Global Burden of Disease Study 2010. The Lancet 2012;380:2224-60. Available from: https://www.thelancet.com/journals/lancet/article/PIIS01406736(12)61766-8/fulltext

21. Thompson C, Branion-Calles M, Harris MA. Estimating bicycling injuries preventable by separated bicycling infrastructure - case study of Bloor-Danforth corridor, Toronto: A technical report submitted to City Building Ryerson 2020 [Date accessed 2021 May 12]. Available from: https://www.ryerson.ca/city-building/news-research/2020/09/lane-change/

22. City of Toronto. Traffic Counts - Cycling. In: Transportation Services. Toronto 2019 [Date accessed 2021 May 12]. Available from: https://open.toronto.ca/dataset/traffic-counts-cycling/

23. Jacoby WG. Loess:: a nonparametric, graphical tool for depicting relationships between variables. Electoral Studies 2000;19:577-613. Available from: https://doi.org/10.1016/S0261-3794(99)00028-1

24. Palm M, Allen J, Widener M, Zhang Y, Farber S, Howell N. Prelimary Results from the Public Transit and COVID-19 Survey. University of Toronto; 2020:1-14. Available from: https://assets.document cloud.org/documents/6888596/Preliminary-Report-on-the-Public-Transitand.pdf

25. City of Toronto. Richmond Street and Adelaide Street Cycle Tracks. In: Transportation Services. Toronto: City of Toronto; 2019 [Date accessed 2021 May 12]. Available from: https://www.toronto.ca/legdocs/mmis/2019/ie/bgrd/backgroundfile-123288.pdf

26. Toronto Police Services, (TPS). Toronto Police Services, Killed or Seriously Injured (KSI). In: Toronto Police Service Public Safety Data Portal. 2020 [Date accessed 2021 May 12]. Available from: https://data.torontopolice.on.ca/datasets/cyclists?geometry $=-79.739 \% 2 \mathrm{C} 43.623 \% 2 \mathrm{C}$ $79.009 \% 2 \mathrm{C} 43.797$

27. Elvik R, Mysen A. Incomplete Accident Reporting: Meta-analysis of studies made in 13 countries. Transportation Research Record 1999;1665:133-40. Available from: https://doi.org/10.3141/1665-18

28. Ministry of Transportation Ontario, (MTO). Ontario Road Safety Annual Reports In: Ontario Ministry of Transportation. Ontario: MTO; 2014 2017 [Date accessed 2021 May 12]. Available from: http://www.mto.gov.on.ca/english/publications/ontario-road-safety-annual-report.shtml

29. Canadian Institute for Health Information, (CIHI). Injury and Trauma Emergency Department and Hospitalization Statistics. CIHI; 2014-2018 [Date accessed 2021 May 12]. Available from: https://secure.cihi.ca/estore/productSeries.htm?pc=PCC1459

30. R Core Team. R: A language and environment for statistical computing. 4.0.2 ed. Vienna, Austria: R Foundation for Statistical Computing; 2020

31. Statistics Canada. CCHS 2014: Data Dictionary Public Use Microdata File (PUMF) - 12-Month 2014 [Date accessed 2021 May 12]. Available from: https://www150.statcan.gc.ca/n1/en/catalogue/82M0013X 
32. Data Management Group, (DMG). Transportation Tomorrow Survey 2016: Design and Conduct of the Survey. 2016:110 [Date accessed 2021 May 12]. Available from:

http://dmg.utoronto.ca/pdf/tts/2016/2016TTS_Conduct.pdf

33. Craw S. Manhattan Distance. In: Sammut C, Webb GI, eds. Encyclopedia of Machine Learning. Boston, MA: Springer US; 2010:639-639. Available from: https://doi.org/10.1007/978-0-387-30164-8 506

34. Jacobsen PL. Safety in numbers: more walkers and bicyclists, safer walking and bicycling. Injury Prevention 2003;9:205-9. Available from: https://www.ncbi.nlm.nih.gov/pubmed/12966006

35. Elvik R, Bjørnskau T. Safety-in-numbers: A systematic review and meta-analysis of evidence. Safety Science 2015. Available from: https://doi.org/10.1016/j.ssci.2015.07.017

36. Davies HT, Crombie IK, Tavakoli M. When can odds ratios mislead? British Medical Journal (Clinical Research Edition) 1998;316:989-91. Available from: https://pubmed.ncbi.nlm.nih.gov/9550961

37. Boisvert N. How the battle over Toronto's new, temporary bike lanes might play out in 2021. CBC 2020 [Date accessed 2021 May 12]. Available from: https://www.cbc.ca/news/canada/toronto/activeto-bike-lanes-future-1.5681154

38. Aldred R, Croft J, Goodman A. Impacts of an active travel intervention with a cycling focus in a suburban context: One-year findings from an evaluation of London's in-progress mini-Hollands programme. Transportation Research Part A: Policy and Practice 2019;123:147-69. Available from: https://doi.org/10.1016/j.tra.2018.05.018

39. Gu J, Mohit B, Muennig PA. The cost-effectiveness of bike lanes in New York City. Injury Prevention 2017;23:239-43. Available from: http://dx.doi.org/10.1136/injuryprev-2016-042057

40. Janstrup KH, Kaplan S, Hels T, Lauritsen J, Prato CG. Understanding traffic crash under-reporting: Linking police and medical records to individual and crash characteristics. Traffic Injury Prevention 2016;17:580-4. Available from: https://www.ncbi.nlm.nih.gov/pubmed/26786061

41. International Traffic Safety Data and Analysis Group. Marrakech Declaration on Better Safety Data for Better Road Safety Outcomes 2017. Available from: https://www.itf-oecd.org/road-safety-data-marrakech-declaration

42. LaRocca R, Yost J, Dobbins M, Ciliska D, Butt M. The effectiveness of knowledge translation strategies used in public health: a systematic review. BioMed Central Public Health 2012;12:751. Available from: https://doi.org/10.1186/1471-2458-12-751

43. Doull M, Welch V, Puil L, et al. Development and evaluation of 'briefing notes' as a novel knowledge translation tool to aid the implementation of sex/gender analysis in systematic reviews: a pilot study. Public Library of Science One 2014;9:e110786. Available from: https://journals.plos.org/plosone/article?id=10.1371/journal.pone.0110786

44. Rigby AS. Statistical methods in epidemiology. III. The odds ratio as an approximation to the relative risk. Disability and Rehabilitation 1999;21:145-51. Available from:

https://doi.org/10.1080/096382899297756

45. Fischer J, Winters M. COVID-19 street reallocation in mid-sized Canadian cities: socio-spatial equity patterns. Canadian Journal of Public Health 2021. Available from: https://doi.org/10.17269/s41997-020-00467$\underline{3}$

46. Karner A, Rowangould D. We Can Get There From Here: New Perspectives on Transportation Equity: National Center for Sustainable Transportation; 2016. Available from: https://escholar-

ship.org/uc/item/9zp565xr
47. Marshall WE, Ferenchak NN. Why cities with high bicycling rates are safer for all road users. Journal of Transport \& Health 2019;13:100539. Available from: https://doi.org/10.1016/j.jth.2019.03.004

48. Ismail S. Incomplete streets, incomplete imaginations: Safe streets for whom? Spacing Toronto 2020 [Date accessed 2021 May 12]. Available from: http://spacing.ca/toronto/2020/08/11/incomplete-streets-incompleteimaginations-safe-streets-for-whom/

49. Harris MA, Branion-Calles M. Changes in Commute Mode Attributed to COVID-19 Risk in Canadian National Survey Data. Findings 2021;February. Available from: https://doi.org/10.32866/001c.19088

50. Amberber N, Howard A, Winters M, et al. Road Traffic Injury During the COVID-19 Pandemic: Cured or a Continued Threat? University of Toronto Journal of Public Health 2021;2. Available from: https://doi.org/10.33137/utjph.v2i1.34737

51. Greenland S, Senn SJ, Rothman KJ, et al. Statistical tests, P values, confidence intervals, and power: a guide to misinterpretations. European Journal of Epidemiology 2016;31:337-50. Available from: https://doi.org/10.1007/s10654-016-0149-3

52. Yu W, Chen C, Jiao B, Zafari Z, Muennig P. The Cost-Effectiveness of Bike Share Expansion to Low-Income Communities in New York City. Journal of Urban Health 2018;95:888-98. Available from: https://doi.org/10.1007/s11524-018-0323-X

53. Kaplan S, Prato CG. A Spatial Analysis of Land Use and Network Effects on Frequency and Severity of Cyclist-Motorist Crashes in the Copenhagen Region. Traffic Injury Prevention 2015;16:724-31. Available from: https://doi.org/10.1080/15389588.2014.1003818

54. Langley JD, Dow N, Stephenson S, Kypri K. Missing cyclists. Injury Prevention 2003;9:376. Available from: http://dx.doi.org/10.1136/ip.9.4.376

55. Nearly $1 \mathrm{M}$ cyclists per year on Bloor. CycleTO, 2019 [Date accessed 2021 May 12]. Available from: https://www.cycleto.ca/news/one-millioncyclists

56. Branion-Calles M, Teschke K, Koehoorn M, Espin-Garcia O, Harris MA. Estimating walking and bicycling in Canada and their road collision fatality risks: The need for a national household travel survey. Preventive Medicine Reports 2021;22:101366. Available from: https://doi.org/10.1016/j.pmedr.2021.101366 